\title{
Creative Learning: A Gateway to Professional Development
}

\author{
Shiv Ram Pandey \\ Tribhuvan University, Nepal \\ shivaram.pandey73@gmail.com
}

\section{Abstract}

This article presents insights on creative learning. It briefly describes the types of creative learning and ways to learning creatively. It discusses the usefulness of creative learning and ends with highlighting the need for creative learning on the part of children, students, teachers and the other individuals. It is truly an enabling, encouraging, engaging and inspiring activity on the part of learners. Creativity cultivates crucial capacity and commitment to learn and earn more conducive knowledge, skills and attitudes.

Keywords: thinking, critical thinking, multiple perspectives, creativity

\section{Pondering on Creative Learning}

The four pillars of learning are: learning to know, learning to do, learning to live together and learning to be. Here, I believe that creativity is going to play a key role in the knowledge-based society. To me creativity is the capacity to give something new in terms of idea, process and product. It is this newness that distinguishes a person or a product from others. Quality, creativity and management are going to play a crucial role in this era. I consider children are the keys in a creative society. It is during childhood that one has the maximum potential for creative development. So, if we have to develop a creative society, we must recognize the crucial phase of childhood in human life in developing the creative potential of the society. It is not only necessary to learn skills and facts, it is more important to learn the art of learning. It is often said that one should not be given fishes but should be taught the art of fishing. I believe that let noble thoughts come to us from every side. Similarly, Swami Vivekananda, (1989) says that education is the manifestation of perfection already in man.

The genesis of the concept of creativity is as old as human life itself. Whatever man creates is not always new. Man is both creative and inventive animal. Necessity has been one of the major motivating factors for creation. One of the major considerations for creation and innovation has been to make life easier. For example; if water is not available within a distance of two kilometers, why not develop a water source near one's house? One of the driving forces for creation 
has been inherent tendency of human beings to look different from others. For example; if we have jewelry, let's have a design of jewelry which others do not have. Rhodes (1961) has classified four types of creativity; person, process, product and press. In the same way, Parker (1963) considers creativity as the art of seeking out, trying out and combining knowledge in a novel way which results in something new.

In simple terms, creativity means mental ability to produce something new and useful. It is better to change a part if the entire product cannot be changed. Creativity may be reflected as a combination of old ideas or products into new forms (Barron, 1961). For example, a tailor may use an old design used in cotton clothes to stitch a woolen coat. Sometimes, a product may be old but packaging may be new. Old ideas appear in new forms.

Everyone believes that creativity is a mental process. Creation comes from human mind. Csikszentmihalyi (1996) has identified three major ingredients in the context of creativity- person, domain and field. A creative person should have an enormous amount of knowledge in the field of work. Creativity has helped society in its evolution from the animal life to the present development. It adds meaning to our life.

Creative learning refers to a type of learning system which provides a learning environment for a person to be creative. One of the main ingredients of creative learning is the generation of self-motivation to perform work as per one's own aptitude and needs. Creative learning is driven by the love for learning. A creative learner learns to examine everything critically with an open mind to bring out something new every time. It is a dynamic process which involves active participation of both the learner and teacher in the teaching learning process. Creative learning is possible in creative schools. It empowers a person to have independent observation, independent analysis and independent conclusion.

A creative person is free even inside the jail. Creative learning is a joyful process. If the process is not joyful, the learner may not be able to make any creative contribution. Creative learning brings dynamism in life which helps in avoiding negativism and he can always find some bright rays of light in the midst of darkness. For instance, if an obstacle is put before an ant, it immediately moves in another direction. If it encounters an obstacle again, it tries a new way. Similarly, a creative person never stops at a particular solution if he encounters any hurdle in implementing that solution. 
Learning is defined as any relatively permanent change in the behavior as a result of practice or experience. Right and left brain play crucial role in bringing change in learning. Left brain emphasizes language and right brain forms and patterns. Gardner (1980) presents seven different styles of learning. They are: verbal, logical, spatial, rhythmic, kinesthetic, interpersonal and intrapersonal. Natural intelligence is associated with what we often refer to as natural consciousness. The persons with natural intelligence are likely to know more by interacting with nature. Enhancing learning ability, learning efficiency, symbolic method of learning, mathematical analysis of symbolic method of learning and special features of symbolic methods of learning come under this process of learning.

This learning process can be conceived in three phases: receptive phase, processive phase and productive phase. Information can be received through visual, auditory, olfactory, and tasting and touch observation. Information is processed in the stages like: memory, thinking, rational and emotional. Productive phase leads to performance of various activities by a person. For example, a person starts writing on a paper using his fingers or starts walking on road.

Education system has to be designed in such a way that the inherent potential of all persons in respect of physical, social, cultural, economic, political and moral dimensions should fully blossom through the process of learning.

\section{Purpose of the Study}

The purpose of the study was to explore the creative learning process, its usefulness and contributions in the realm of learning.

\section{Method of the Study}

The available literature has been reviewed, interpreted, and analyzed in order to explore creative learning process, its usefulness and contribution. The conclusion is arrived with inductive process of analyzing the available information and insights.

\section{Ways to be Creative}

The individuals can employ different ways to be creative. Some of them have been discussed here:

Creativity through education. It is better to learn from our experiences in the area of formal, informal and semiformal education with particular emphasis 
on experiences. Even folk learning system believes every occasion is a learning occasion. Activity approach, multiple objectives, group effort, participatory method, open ended activities, festive mood of learning, newness every time, fixed aim, activities for all time, learning facilitators, emotional linkage to learning, creators are god, holistic learning system, relevant teaching methodology, design new learning occasions and fixed period come under it.

To facilitate creative learning process, we need a new teaching learning methodology. Learning to learn really needs to be understood in terms of the following questions: why learn? Who may learn? Where to learn? When to learn? What to learn? How to learn? Man is a learning animal. Learning in a planned manner is a necessity to meet the high level of expectations. People of all age and all walks of life can learn and go on learning continuously from the first till the last day of their lives. Every occasion is a learning occasion. Every person, animate and inanimate object in the world is a learning object, learning facilitator and learner. There is no end to the extent of acquiring knowledge. The fundamental principle of this learning is to begin from "know thyself or to "learn about yourself before you learn about others." An atmosphere of happiness provides a motivating environment for creative learning. Games basically provide a good opportunity to perform an activity in an atmosphere of joy. Let classrooms be a playground too. They provide a forum for faster learning. There are three kinds of interactions: teacher learner interaction, learner material interaction and learner- learner interaction. Curiosity is the base of creative learning. Csikszentmihalyi (1996) has suggested the following plan for development of curiosity. Try to be surprised by something every day. Try to surprise at least one person everyday. Write down each day what has surprised you and how you surprised others. When something strikes a spark of interest, follow it.

Delor's report (1996) presents the following four pillars of creative learning: learning to know, learning to do, learning to live together and learning to be. Self learning is the base of creative learning. All efforts have to be made to make learners competent in the art of self learning. Lessen competition, enhance cooperation is the feature of present education system.

One of the major considerations for designing activities for creative learning process is to ensure that the activity leads to development of natural learning process. Symbol learning is the first step towards creative learning process. It requires study of symbol reading, learning about symbolic relationship and creation of new symbols. In the same way, creating new patterns is one of the main tasks in the development of creativity. 
The primary task of any elementary programme is to ensure full development of the natural learning process of a child. We must design the educational methodology to suit the specific needs of the child. Children must perform activities to develop reception of information into the brain through all sensory organs. The sensory organs must be fully sharpened and developed to facilitate easy and fast flow of information. Information is transmitted through multi-sensory operations. Use of machines enhances the power of observation. Mixing learning techniques in teaching can be used in creative learning. To enhance the efficiency of the transmission of information in processive phase, we must have better storage of information in memory system, efficient handling of information during thinking and proper development of better emotional management system. Activities have to be designed to develop memory in such a way that the information can be stored and reproduced at will. Sing songs for lasting memory, pictures as memory aid, arranging information in logical sequences, learn story, remember forever, symbolizing matter are the activities we can conduct in creative learning.

Thinking is the most important part of mental activity. It is the better thinking capacity which establishes superiority of human beings over animals. It is thinking which has steered the development of culture and civilization. Hence, to develop a fast, clear and strong thinking ability is an essential aspect of learning process. It is an implicit problem solving behaviour. Brainstorming sessions, learning the art of questioning, performing imagination development exercises, developing emotional control are useful in creative learning. To develop the production phase of learning, we should try to develop different competencies of communication and presentation of ideas. One of the main objectives of creative learning is to enhance creative flow in children.

Creating new learning occasions. Learning occasions are basically natural or organized occasions which facilitate learning process rainbow. Although we keep on learning all the time, learning occasions accelerate the pace of learning. A normal chat may be done for entertainment but it would be a big occasion for learning, if it were structured with the avowed aim of facilitating learning process. For promotion of creative learning one of the primary tasks is to create as many learning occasions as possible. Activity card or learning card is very useful. Since children have to spend maximum time at home, priority should be given to enrichment of family occasions with learning content. Swami Dayananda has identified father, mother and teacher to be the three pillars of education of a child. It is commonly said that a man is knowledgeable, if he is under the guidance of learned mother, father and teacher. Interacting with children during bedtime is good. Dining time is another great occasion for learning. Children start 
learning in the kitchen as well. It has been found that if a child is read a storybook right from birth, he may start reading the book right from the age of 3-4 years.

We realize that nature is the storehouse for ideas for creations. Let every garden be a learning garden. Let every museum be a culture learning centre. Let every temple be a temple of learning. Festivals are great occasions for learning. Playing games in the family can be an occasion not only for fun and entertainment but can also be used as learning activity.

Some people think that school is just like a workshop, where raw materials like children are sent for processing. Every moment spent in the school and outside is a learning moment. The writer told us to make children learners not just the students. Learning can take place while children are on the bus journey. Assembly is a great learning occasion. Children love music which makes learning lively and enjoyable. Children also learn from exhibitions. Creative use of gallery and boundary walls, creative use of floors, classroom library, creative use of playground, learning through games and sports, gardens and children's park are the occasions for creative learning.

I finally present my views on monitoring and evaluation and stress the need to come up with modern examination system which helps learners to take part cooperatively rather than competitively in the examination. It is equally important to know as to what a child does not know than to know to what extent he knows. Basically, monitoring of creative learning requires monitoring of self-learning skills of the child. It has to be oriented towards the need of the child. Each child is the unique creation of god and as such his uniqueness must be respected. Each child has a separate pace of learning; each has separate style of learning.

So, each child should be monitored separately. Evaluation should be done to help the child in this learning process rather than grading him for any external agency. He should not be compared with other children for no two children are ever comparable. For the purpose of monitoring, one has to monitor the development of power of observation by properly designing learner specific system of evaluation. The development of power of expression has to be needbased. Evaluation process should facilitate the learner to achieve creative flow in the particular area of learning. Evaluation can be done in many ways. It should be a joyful process. Self evaluation will lead a child to perform better and better by enjoying the sheer pleasure of achievement. He or she should be motivated to do hard work to acquire necessary information pertaining to that subject. 


\section{Advantages of Creative Learning}

Creativity provides tremendous joy to learn and earn knowledge. I found it quite thoughtful. It highlights very much on thinking process. It is through thinking process, one can give way to creativity. Experience gives birth to creative learning. The early age is more important part to learn creative things. I believe that man is a learning animal. Learning in a planned manner is a necessity to meet the high level of expectations. People of all age and all walks of life can learn and go on learning continuously from the first till the last day of their lives. Every occasion is a learning occasion. The writer focuses his or her attention on the development of concentration, memory, thinking, imagination, visualization, power of observation and emotional management. Learning doesn't have any limitations. It can be learnt formally, informally and non-formally. Anybody can learn at anytime, anywhere and with anybody as well. We believe that all people have strengths and talents that are important to recognize, develop, and use throughout life. We also believe that people of all ages can improve their skills and ability to use creative and critical thinking, problem solving, and decision making, and that research on learning style helps us to understand how people develop and use their talents in unique and personal ways.

Academic advantages. It maximizes learning potential. It succeeds on all educational levels. It understands how to best study and score better on exams and tests. It overcomes limitations in the classroom. It reduces frustration and stress levels. It expands existing learning strategies.

Personal advantages. It improves self-confidence and self-esteem. People learn how to best use brain. We gain insight into own strengths as well as weaknesses. We learn how to enjoy learning more. We develop a motivation for learning. We learn how to maximize natural abilities and skills.

Professional advantages. It makes us stay up to date on professional topics. It gains an edge over the competition. It manages teams in a more effective manner. We learn how to deliver more effective presentations. One can improve sales skills. One can increase earning power.

\section{Conclusion}

By and large I have realized that life is creative. There is hardly any bigger joy than the joy of creativity. Learning takes place everywhere. There is no bound of time, place and age in the case of learning. Childhood is the most important 
part for better learning. Learning is meant for earning knowledge, skills, attitudes and values. Creative people's attitude determines their academic altitude. Action speaks louder than the words. So, creative people are action-oriented. Creative people create new knowledge and new things. Creative learning adds newness, freshness, novelty, creation, variety and new ways of survival in one's life. Learning is more the matter of perspiration than the matter of inspiration. To my understanding, it helps everybody to follow the path of success with devotion, dedication, discipline, determination and commitment. To make one's life meaningful, successful and beautiful, creative learning is really useful and fruitful to all. Finally, I would like to suggest everybody to learn how to be creative and inventive in their life.

\section{References}

Baron, F. (1961). Psychological validity and creative freedom. New York: Willy.

Csikszentmihalyi, A. (1996). Creativity. Nw York: Harper Collins.

Delors, J. (Report) (1996) Learning: The treasure within. Paris: UNESCO.

Parker, C.F. and Sinha P. (1963). Effect of home environment and school climate onauthoritarianism, creativity and fear of failure. PhD. thesis submitted to Patna University. Patna, India.

Rhodes, M. (1961). An analysis of creativity. Phi Delta Kappan,42,305-310.

Vivekananda, S. (1989). The complete works of Swami Vivekananda. Calcutta: Advaita Ashram.

Gardner, H. (1980). Human intelligences. London: Yorkshire Publication. 